\title{
Isolation of Components with Antimicrobial Property from the Donkey Milk: A Preliminary Study
}

\author{
Filomena Nazzaro*, ${ }^{*}$, Pierangelo Orlando ${ }^{2}$, Florinda Fratianni ${ }^{1}$ and Raffaele Coppola ${ }^{1}$ \\ ${ }^{1}$ Istituto di Scienze dell'Alimentazione, CNR-ISA, Via Roma, 6483100 Avellino, Italy \\ ${ }^{2}$ Istituto di Biochimica delle Proteine, CNR-IBP, Via P. Castellino, 80124 Napoli, Italy
}

\begin{abstract}
The presence of components in donkey milk, different from lysozyme, capable of inhibiting the growth of pathogenic microorganisms was investigated. Milk was acidified, hydrolyzed with pepsin, and analyzed by HPLC. The chromatographic fractions were collected in 5 main pools that, after the removal of lysozyme, were analyzed by microelectrophoresis; antimicrobial activity was evaluated against the pathogens Bacillus cereus, Staphylococcus aureus, Enterococcus faecalis, and Escherichia coli. Hydrolyzed milk showed a protein pattern ranging from 0.78 to $25.2 \mathrm{kDa}$. It was active against all pathogenic strains tested, with inhibition halos ranging from $4.3 \mathrm{~mm}$ (against E.coli) to $17.4 \mathrm{~mm}$ (versus E.faecalis). Among the pools collected after HPLC step, pool "b" resulted to be the most rich in protein bands, most of them with a molecular weght less than $20.4 \mathrm{kDa}$, and the most effective against all the pathogens, except against E. coli. Pool "a", was active versus E. coli and B. cereus and contained only two bands, at 0.31 and $8.3 \mathrm{kDa}$, this last band probably responsible for its antimicrobial activity and chemically different from the other ones with a similar MW present in pools "c" and "e" that did not inhibit the growth of the pathogenic strains. This finding highlights the presence of bio molecules released during proteolytic hydrolysis that may contribute to the antimicrobial activity in donkey milk and play a significant role in the host defense system.
\end{abstract}

Keywords: Donkey milk, antimicrobial, HPLC, micro-electrophoresis.

\section{INTRODUCTION}

Milk is considered a good medium for many microorganisms, such as lactic acid bacteria, since it contains essential nutrients and meets physical environment requirements for microbial growth. Milk additionally provides an array of defence protein factors, such as lactoperoxidase, lactoferrin, lysozyme, N-acetyl- $\beta$-D glucoaminidase and immunoglobulins, that have the capability to kill or inhibit a large spectrum of pathogen microorganisms [1]. The digestion of milk proteins is an important mechanism to create peptides, which have important nutritional values and physiological roles. Several antihypertensive, immunomodulating, opiate-like or antithrombotic protein fragments have been described in milk [2]. Small proteolytic fragments of both bovine and human lactoferrin have been shown to exhibit antimicrobial and bacteriostatic activities, the latter of which was thought to deprive microorganisms of iron [3]. Donkey milk has recently stimulated scientific interest due to its attractive nutrient and functional contents. Because of its chemical composition similar to human milk, it is considered a valid alternative for infants with severe (Ig)E-mediated cow's milk protein allergy [4-6]. Additionally, donkey milk is a strong vasodilator, making it potentially useful in the prevention of atherosclerosis [7], and it has been shown to exert an in vitro suppressing action against human lung tumors [8]. At present, this milk is principally utilized in Asia, Africa and eastern Europe, where donkeys are still being traditionally bred.

*Address correspondence to this author at the Istituto di Scienze dell'Alimentazione, CNR-ISA, Via Roma, 6483100 Avellino, Italy; Tel: +390825299102; Fax: +390825781585; E-mail: mena@isa.cnr.it
The protein content of donkey milk is similar to that in breast and mare milk. The milk is predominantly rich in whey proteins, such as $\alpha$-lactalbumin, $\beta$-lactoglobulin, which range from $35 \%$ to $50 \%$ of the total nitrogen fraction, compared to $20 \%$ of in cow's milk. The total casein content is about $8.7 \mathrm{~g} / \mathrm{l}$, which is remarkably close to the amount found in human milk [9]. Donkey milk is particularly rich in lysozyme, a well-known natural antimicrobial agent which catalyses the hydrolysis of glycosidic bonds of mucopolysaccharides in bacterial cell walls [10]. Lysozyme may contribute to the low bacterial concentration in donkey's milk [9,11]. This molecule, which is also found in human and bovine milk, decreases the incidence of disease, mainly diarrhea, and these occurrences are generally much lower in breast-fed infants than in formula-fed infants. Based on the observation of human milk suppressing the growth of special bacteria in the intestine of breast-fed infants and the similar protein composition of donkey and human milk, the aim of our study was to investigate the presence of protein components in donkey milk capable of inhibiting the growth of Bacillus cereus, Staphylococcus aureus, Enterococcus faecalis and Escherichia coli pathogenic strains after treating the milk with pepsin, an enzyme that simulates conditions in the host stomach.

\section{MATERIALS AND METHODS}

\subsection{Hydrolysis of Donkey Milk}

Donkey milk was pooled by an organic breeding in the Salerno province (Italy). It was hydrolyzed following the method of Liepke et al. [12]. After acidification with $\mathrm{HCl}$ to a $\mathrm{pH}$ of 3.5 , it was incubated with pepsin $(20 \mathrm{mg} / \mathrm{g}$ protein $)$ at $37^{\circ} \mathrm{C}$ for $2 \mathrm{~h}$ and thereafter boiled for $5 \mathrm{~min}$ to stop the 
hydrolysis process. After this, the supernatant was recovered and the fat was decanted off. A $0.1 \%$ trifluoroacetic acid (TFA) was added and, after vigorous mixing, samples were centrifuged $\left(20 \mathrm{~min}\right.$ at $6,000 \mathrm{x} \mathrm{g}$ at $\left.4^{\circ} \mathrm{C}\right)$ to remove floating particles.

\subsection{Chromatographic Analysis}

Chromatographic analysis was performed by RP-HPLC procedure using a Gold System apparatus equipped with an ultraviolet detector (Beckman, CA, USA). The analytical profile was obtained through fractionation on Khromasyl C18 at $\lambda=214 \mathrm{~nm}$ with a gradient A (water $+0.01 \% \mathrm{TFA}$ ) towards B $(95 \%$ acetonitrile $+0.01 \%$ TFA). Fractions obtained by HPLC were collected in some pools, freeze dried and stored at $-25^{\circ} \mathrm{C}$ until the antimicrobial testing and electrophoretic analysis were conducted.

\subsection{Microorganism Strains, Growth Conditions and An- timicrobial Activity Testing}

The inhibition halos test on agar plates was employed to investigate the antimicrobial activity of hydrolyzed milk before and after HPLC. The test was performed against pathogenic Gram-positive strains Bacillus cereus (DSM 4313 and DSM 4384), Staphylococcus aureus (DSM 25923) and Enterococcus faecalis (DSM 2352) and the Gramnegative strain Escherichia coli (DSM 8579). All strains were purchased by Deutsche Sammlung von Mikroorganismen und Zellkulturen GmbH (DSMZ Germany). Each strain was incubated at $37^{\circ} \mathrm{C}$ for $18 \mathrm{~h}$ in Nutrient Broth (Oxoid, UK).The microbial suspensions (approximately $10^{8}$ colony forming units $/ \mathrm{ml}$ ) were spread onto $20 \mathrm{ml}$ nutrient agar in Petri dishes $(\varnothing 90 \mathrm{~mm})$. After $10 \mathrm{~min}$ under sterile conditions at room temperature, sterile Whatman no. 1 paper filter discs (Ø $5 \mathrm{~mm}$ ) were individually placed on the inoculated plates and saturated with either milk after hydrolysis or the fractions obtained by HPLC. After $30 \mathrm{~min}$, all plates were incubated at $37^{\circ} \mathrm{C}$ for $24-48 \mathrm{~h}$, depending on bacterial strain. The diameter of the zone of inhibition on plates was measured and the antimicrobial activity was expressed in $\mathrm{mm}$. Sterile deionized water and pure dimethyl sulfoxide (DMSO) $(10 \mu 1)$ were used as negative controls. Chloramphenicol (66 $\mu \mathrm{g})$ served as positive controls. Samples were tested in triplicate and results expressed as mean \pm standard deviation. The most active antimicrobial fractions were analyzed by microcapillary electrophoresis.

\subsection{Lab-on-a-Chip Capillary Electrophoresis}

Protein content was evaluated following the method of Bradford [13]. $4 \mu \mathrm{l}$ samples were mixed with $2 \mu \mathrm{l}$ of a Protein 260 LabChip denaturing solution, and lower and upper markers (all from BioRad, Milano, Italy). Samples were incubated at $100^{\circ} \mathrm{C}$ for $3 \mathrm{~min}$ and mixed afterward with $84 \mu \mathrm{L}$ of deionised and filtered water. The molecular weight markers were prepared according to manufacturer's instructions (Protein 260 Assay protocol from BioRad) and treated as described above. Separation and detection were performed with Experion apparatus (BioRad, Milano, Italy) using fluorescence detection with a $10-\mathrm{mW}$ semiconductor laser at 630 $\mathrm{nm}$. Fractionation was based on protein size. The data were analyzed using the Experion software.

\section{RESULTS AND DISCUSSION}

Some functional properties of donkey milk could be ascribable not only to its probiotic activity [14], but also to the presence of protective factors, like immunoglobulins and peptides with antibacterial and immunomodulating activity [15]. Antimicrobial activity in donkey milk is due to the high content of lysozyme; however, like other types of milk, such activity might be also due to the presence of other substances, which can originate from the digestion of proteins. In this experiment, we hypothesized that hydrolyzing donkey milk proteins could result in the release of additional components (other than lysozyme) capable of inhibiting the growth of pathogenic microorganisms. This was hypothesized because human milk exhibits a bacterial modulating effect following digestion [12] and has a similar chemical composition of donkey milk. The inhibitory activity of donkey milk after hydrolysis was tested against different pathogenic microorganisms by the inhibition halo test (Table 1). On the whole, the milk displayed a different inhibitory capability. This finding highlights the presence of bio-molecules generated by the hydrolysis of milk that may contribute to its antimicrobial activity. Hydrolyzed milk was active against $S$. aureus and E. faecalis, in dose-dependent manner with halos ranging from $16.3 \mathrm{~mm}$ (S. aureus) to about $17.30-17.40 \mathrm{~mm}$ (E. faecalis). A dose dependent effectiveness was observed against $B$. cereus DSM 4313; milk was less active against $B$. cereus DSM 4384, which demonstrates a strain-dependent activity within the same species. The most resistant strain was the toxicogenic E. coli DSM 8579 (8 $\mathrm{mm}$ inhibition halo). Fig. (1) shows the chromatographic profile of milk

Table 1. Antimicrobial Activity Exhibited by Donkey Milk After Hydrolysis with HCl, Incubation with Pepsin and Subsequent Treatment with TFA. Data represent the mean ( \pm deviation standard in parentheses) of three independent experiments and are expressed as $\mathrm{mm}$ of inhibition halo, which does not include the diameter of the paper disk.

\begin{tabular}{|c|c|c|c|}
\hline Strains & $\mathbf{4 0} \boldsymbol{\mu \mathbf { l }}$ & $\mathbf{6 0} \mu \mathbf{l}$ & $\mathbf{8 0} \boldsymbol{\mu l}$ \\
\hline \hline E.coli DSM 8579 & $4.3( \pm 0.6)$ & $6.3( \pm 0.6)$ & $7.6( \pm 0.6)$ \\
\hline B. cereus DSM 4313 & $11.6( \pm 1.1)$ & $15.3( \pm 0.6)$ & $17.3( \pm 1.1)$ \\
\hline B. cereus DSM 4384 & $10.0( \pm 1.5)$ & $12.7( \pm 1.1)$ & $12.6( \pm 0.6)$ \\
\hline S. aureus DSM 25923 & $16.6( \pm 0.6)$ & $16.3( \pm 0.6)$ & $16.3( \pm 1.3)$ \\
\hline E. faecalis DSM 2352 & $17.3( \pm 0.9)$ & $17.3( \pm 1.1)$ & $17.4( \pm 1.0)$ \\
\hline
\end{tabular}


b

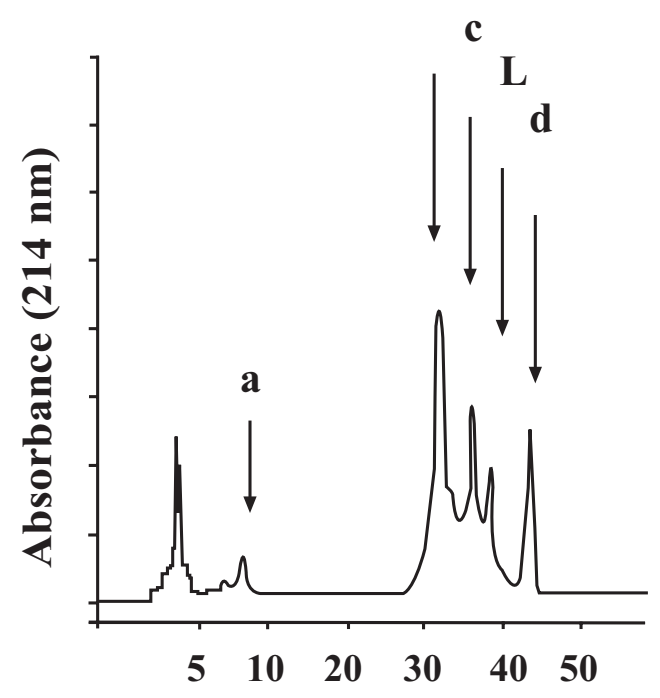

\section{Retention time (min)}

Fig. (1). HPLC analysis of donkey milk after treatment with $\mathrm{HCl}$ and pepsin. Arrows indicate the main pools collected during the chromatographic step, indicated as a, b, c, d, and e, depending from the retention time.

after treatment with $\mathrm{HCl}$ and pepsin. All fractions were collected in 5 main pools: (1) pool a, contained fractions eluted until 8 minutes, (2) pool b included fractions eluted from 30 to 32 minutes, (3) pool c comprised fractions eluted from 34 to 37 minutes, (4) pool d, eluted between 39 and $40 \mathrm{~min}$, containing lysozyme (as evaluated by the retention time of the pure molecule), and (5) pool e consisted of fraction collected between 42 and $45 \mathrm{~min}$. Because the hydrolysis of milk did not eliminate lysozyme, the antimicrobial activity observed in the acidified milk could be due to the high content of this well-known natural antimicrobial bio-molecule. For this reason, after the chromatographic step, pool d was removed. The other pools were freeze dried, re-suspended in $200 \mu \mathrm{l}$ of sterile deionized water, and $8 \mu 1$ used to test their potential antimicrobial activity. As shown in Table 2, pool b was the most efficient, particularly against $E$. faecalis and $B$. cereus DSM 4384 (inhibition halos of 14.7 and 13.7, respectively). The behavior exhibited by the two strains of $B$. cereus, tested after the chromatographic step, was opposite to that observed before, resulting strain DSM 4384 more sensitive than DSM 4313. The antimicrobial activity showed against $B$. cereus 4313 before fractionation was principally due to lysozyme; inversely, the chromatographic step allowed the release other fraction/s responsible for the antimicrobial activity of milk against B. cereus 4384 . Pool b resulted less effective activity against $S$. aureus $(9 \mathrm{~mm})$ and ineffective activity against $E$. coli. Literature data concerning the inhibitory effect of donkey milk against different bacterial species is extremely limited. Based on the results above shown, antimicrobial activity of donkey milk varied according to the indicator microorganisms. After the hydrolysis and before the HPLC step, the high concentration of lysozyme could have affected the inhibitory activity [16-19]. However, as demonstrated in our work, after the elimination of lysozyme, other portions exhibited the antimicrobial effect. Table 3 shows the molecular weights of the bands present in the pools that revealed a MW ranging from 0.31 to 33.15 $\mathrm{kDa}$. Pool $\mathrm{b}$ revealed the widest antimicrobial activity, and also was the richest in $\mathrm{N}$ components, ranging from 0.74 to $33.12 \mathrm{kDa}$. Two molecules of about 20.0 and $25.22 \mathrm{kDa}$ were detected both in pool $\mathrm{b}$ and in the hydrolysed milk: they, being in our consideration the potentially most important biomolecules after lysozyme, could be involved in the antimicrobial activity exhibited against $S$. aureus, E. faecalis and the two strains of B. cereus. Different authors [20-23] reported that the protein composition of donkey milk ranged from $80.0 \mathrm{kDa}$ (relatively assigned to lactoferrin) to 66.0 $\mathrm{kDa}$ (seric albumin) and $60 \mathrm{kDa}$ (immunoglobulins); other proteins ranging from 42 to $23 \mathrm{kDa}$ corresponded to the different casein fractions. Bands with a MW of 14.6 and 14.15 $\mathrm{kDa}$ were related to lysozyme and lactoferrin, respectively. A band of $20.0 \mathrm{kDa}$, found both in pool $\mathrm{b}$ and in the hydrolyzed milk, could be ascribable to the $\beta$-lactoglobulin, already documented in donkey milk $[21,23]$ and capable of exerting effective antimicrobial activity, as demonstrated in other milk [24]. Therefore, this molecule was absent in the other pools that did not show bands higher than $10 \mathrm{kDa}$, except pool e, which contained a molecule of $13.9 \mathrm{kDa}$. Interestingly, among the other pools, only pool a exerted an inhibitory effect against $E$. coli and B. cereus DSM 4313 (Table 2). It showed only two molecules with a MW of 0.31 and $8.30 \mathrm{kDa}$. This last might be primarily responsible for the antimicrobial activity exhibited by pool "a" and chemically different from the other ones with a similar MW present in pools $\mathrm{c}$ and $\mathrm{e}$ that did not inhibit the growth of the two pathogenic strains.

\section{CONCLUSIONS}

The preliminary results show that donkey milk contains many antimicrobial components further than lysozyme. These components might play an important role in the im-

Table 2. Antimicrobial Activity Exhibited by the Different Pools of Fractions After HPLC. Data represent the mean $( \pm$ deviation standard in parentheses) of three independent experiments and are expressed as mm of inhibition halo, which does not include the diameter of the paper disk.

\begin{tabular}{|c|c|c|c|c|c|}
\hline Strains & Pool a (0-8 min) & Pool b (30-32 min) & Pool c (34-37 min) & Pool e (42-45 min) & Chloramphenicol 66 $\mu$ g \\
\hline \hline E.coli DSM 8579 & $11.7( \pm 0.6)$ & - & - & - & $15.1( \pm 0.5)$ \\
\hline B. cereus DSM 4313 & $7.0( \pm 0.6)$ & $9.0( \pm 1.0)$ & - & - & $17.2( \pm 0.4)$ \\
\hline B. cereus DSM 4384 & - & $13.7( \pm 1.15)$ & - & - & $17.9( \pm 0.7)$ \\
\hline S. aureus DSM 25923 & - & $9.0( \pm 1.00)$ & - & - & $12.6( \pm 1.9)$ \\
\hline E. faecalis DSM 2352 & - & $14.7( \pm 0.3)$ & - & - & $24.1( \pm 2.0)$ \\
\hline
\end{tabular}


Table 3. Molecular Weight (in kDa) of the Bands Present in the Hydrolyzed Milk and in the Pools a, b, c, and e, Obtained Through by Lab-on Chip Microcapillary Electrophoresis. Data indicate the mean ( \pm deviation standard in parentheses) of three independent experiments.

\begin{tabular}{|c|c|c|c|c|}
\hline (kDa) & (kDa) & (kDa) & (kDa) & (kDa) \\
\hline $0.78( \pm 0.06)$ & $0.31( \pm 0.03)$ & $0.74( \pm 0.13)$ & $7.55( \pm 0.92)$ & $7.70( \pm 1.04)$ \\
\hline $1.12( \pm 0.11)$ & $8.30( \pm 1.18)$ & $1.02( \pm 0.24)$ & $10.3( \pm 1.13)$ & $13.92( \pm 1.45)$ \\
\hline $7.23( \pm 1.12)$ & & $1.08( \pm 0.1)$ & & \\
\hline $7.57( \pm 1.01)$ & & $1.10( \pm 0.04)$ & & \\
\hline $10.47( \pm 1.45)$ & & $5.53( \pm 0.57)$ & & \\
\hline $14.75( \pm 1.51)$ & & $7.51( \pm 0.92)$ & & \\
\hline \multirow[t]{3}{*}{$25.22( \pm 1.02)$} & & $25.22( \pm 1.19)$ & & \\
\hline & & $31.29( \pm 2.41)$ & & \\
\hline & & $33.15( \pm 2.11)$ & & \\
\hline
\end{tabular}

provement of the host defense system of newborn and small infants which either cannot be nourished by human milk or are allergic to other milks.

\section{REFERENCES}

[1] Min S, Harris L, Krochta JM. Antimicrobial effects of lactoferrin, lysozyme, and the lactoperoxidase system and edible whey protein films incorporating the lactoperoxidase system against Salmonella enterica and Escherichia coli O157:H7. J Food Sci 2005; 70: 3328.

[2] Meisel H, Frister H, Schlimme E. Biologically active peptides in milk proteins. Zeitschrift für Ernährungswissenschaft 1989; 28: 267-78.

[3] Tomita M, Takase M, Wakabayashi H, Bellamy W. in:. Lactoferrin: Structure and Function, Plenum Press, New York, London, 1994, p. 209.

[4] Carroccio A, Cavataio F, Montaldo G.D, Amico D, Alabrese L, Iacono G. Intolerance to hydrolyzed cow's milk protein in infants: Clinical characteristics and dietary treatment. Clin Exp All 2000; 30: 1597-603.

[5] Iacono G, Carroccio A, Cavataio F, Montalto G, Soresi M, Balsamo V. Use of ass' milk in multiple food allergy. J Pediatr Gastroenterol Nutr 1992; 14: 177-81.

[6] Monti G, Bertino E, Muratore MC, et al. Efficacy of donkey's milk in treating highly problematic cow's milk allergic children: An in vivo and in vitro study. Ped Allergy Immunol 2007; 18: 258-64.

[7] Tafaro A, Magrone T, Jirillo F, Martemucci G, D'Alessandro A, Amati L, Jirillo E. Immunological Properties of Donkey's Milk: Its Potential Use e in the Prevention of Atherosclerosis. Curr Pharm Des 2007; 13: 3711-7.

[8] Mao X, Gu, J, Sun Y, Xu S, Zhang X, Yang H, Ren F. Antiproliferative and anti-tumor effect of active components in donkey milk on A549 human lung cancer cells. Intern Dairy J 2009; 19: 703-8.

[9] Salimei E, Fantuz F, Coppola R, Chiofalo B, Polidori P, Varisco G. Composition and characteristics of ass's milk. Anim Res 2004; 53: 67-78.
[10] Chiavari C, Coloretti F, Nanni M, Sorrentino E, Grazia L. Use of donkey's milk for a fermented beverage with lactobacill. Lait 2005; 85: 481-90

[11] Malacarne M, Martuzzi F, Summer A, Mariani P. Protein and fat composition of mare's milk: some nutritional remarks with reference to human and cow's milk. Int Dairy J 2002; 12: 869-77.

[12] Liepke C, Zucht HD, Forssmann WG, Standker, L. Purification of novel peptide antibiotics from human milk. J Chromatogr B 2001; 752: 369-77.

[13] Bradford MM, A Rapid and Sensitive Method for the Quantitation of Microgram Quantities of Protein Utilizing the principle of protein-dye binding. Analyt Biochem 1976; 72: 248-54.

[14] Nazzaro F, Anastasio M, Fratianni F, Orlando P. Isolation and identification of probiotic lactic acid bacteria from raw donkey milk. Intern J Prob Preb 2008; 3: 374.

[15] Vincenzetti S, Polidori P, Vita A. Nutritional characteristics of donkey's milk protein fractions in Protein Research Progress edited by Alan B. Boscoe and Charles R Listow 2008. 159-190. Nova publisher eds, New York.

[16] Forrer K, Hammer S, Helk B, Chip-based gel electrophoresis method for the quantification of half-antibody species in IgG4 and their by- and degradation products. Anal Biochem 2004; 334: 8188.

[17] Guo HY, Pang K, Zhang XY, Zhao L, Chen SW, Don ML. Composition, Physiochemical Properties, Nitrogen Fraction Distribution, and Amino Acid Profile of Donkey Milk. J Dairy Sci 2007; 90: $1635-43$.

[18] Kamysu W, Okroj M, Lukasiak J. Novel properties of antimicrobial peptides. Acta Biochim Pol 2003; 50: 236-9.

[19] Zhang XY, Zhao L, Jiang L, Dong ML, Ren FZ. The antimicrobial activity of donkey milk and its microflora changes during storage Food Control 2008; 19: 1191- 5.

[20] Businco L, Giampietro P, Lucenti P, et al. Allergenicity of mare's milk in children with cow's milk allergy. J All Clin Immun 2000; 105: 1031-4.

[21] Cunsolo V, Saletti R, Muccilli V, Foti S. Characterization of the protein profile of donkey's milk whey fraction. J Mass Spectrom 2007; 42: 1162-74. 
[22] Fantuz F, Vincenzetti S, Polidori P, Vita A, Polidori F, Salimei E. Study on the protein fractions of donkey milk, In Proceedings of the XIV A.S.P.A. Congress, 2001, 635-637. Firenze, Italy.

[23] Vincenzetti S, Polidori P, Mariani P, Cammertoni N, Fantuz F. Vita A. Donkey's milk protein fractions characterization. Food Chem 2008; 106: 640-49.
[24] Pan Y, Shiell B, Wan J, et al. The molecular characterisation and antimicrobial properties of amidated bovine $\beta$ - lactoglobulin. Int Dairy J 2007; 17: 1450-9.

Received: May 07, 2010

(C) Nazzaro et al.; Licensee Bentham Open.

This is an open access article licensed under the terms of the Creative Commons Attribution Non-Commercial License (http://creativecommons.org/licenses/by-nc/3.0/) which permits unrestricted, non-commercial use, distribution and reproduction in any medium, provided the work is properly cited. 